\title{
"Os vetos do prefeito": políticas de um plano municipal de educação numa sessão legislativa
}

\author{
"The Vetoes of the mayor": the policies of a municipal \\ plan of education in a legislative session
}

\section{Cleiton Vieira}

Doutorando e mestre em Antropologia Social pela UFRN, membro do GCS - Grupo de Pesquisa em Gênero, Corpo e Sexualidade (UFRN), Bolsista CAPES, Research Scholar na School of Anthropology, University of Arizona, com pesquisa sobre saúde, ativismo e política, enfatizando formação do campo médico e de construção do cuidado e direitos envolvendo transexualidades.

\section{Resumo:}

Neste trabalho objetiva-se descrever as experiências dos vereadores na formulação do Plano Municipal de Educação de Natal (PME), partindo da sessão legislativa de consideração dos vetos às suas emendas. Esse momento é entendido aqui como uma situação social nos termos de Max Gluckman (2010), no qual foram discutidos e votados dois dos onze vetos do prefeito às emendas parlamentares ao Projeto de Lei do PME criado pela Prefeitura. Os planos de educação têm uma longa história no Brasil, mas apenas na última década foram consolidados como leis de caráter participativo e de discurso humanitário nos três níveis de poderes. Interessando-me em entender como os legisladores compreendem e vivem a política diante da formulação de uma política pública, observou-se etnograficamente a perspectiva dos próprios atores que vivem e constituem sua participação na criação de um Plano de Educação da municipalidade. Para os vereadores, as outorgas de vetos às suas mudanças no projeto de lei pelo Prefeito excederam o limite do aceitável, configurando-se em vetos políticos que impedem os legisladores de "participar" da governança da cidade. Isso culminou em uma desvinculação entre veto e prefeito por parte de sua base aliada, e de vinculação pessoalizada por parte da "oposição. A pesquisa que compreende esse trabalho constituiuse de observação etnográfica de uma sessão parlamentar na manhã de 7 de junho de 2016 e de convivência com funcionários de um dos gabinetes, além da análise concomitante de documentos provenientes do "processo legislativo", isto é, pareceres técnicos da Procuradoria Legislativa e da Procuradoria do Executivo atrelados a matéria do PME. 
Palavras-chave: Antropologia da Política, Governança, Plano Municipal de Educação, Vereadores, Legislativo.

\section{Abstract:}

In this paper the objective is to describe the experiences of the city councilors of Natal/RN, Brazil in the formulation of the Municipal Plan of Education of Natal (PME), starting from the legislative session for consideration of the vetoes to their the amendments. This moment is understood as a social situation, in Max Gluckman's terms, in which two of the eleven vetoes from the Mayor to the amendments to the bill of the SME created by him were discussed and voted. The plans of education have a long history in Brazil, but only in the last decade they were consolidated as laws of participatory nature and of humanitarian discourse in the three levels of power. Seeking to understand how legislators understand and live by the policy on the formulation of a public policy, the perspective of the actors, who live and constitute their participation in the creation of a Plan of Education of the municipality, was ethnographically observed. To the councilors, vetoes to the changes in the draft law by the Mayor exceeded the limit of what is acceptable, by configuring political vetoes that prevent the lawmakers to "participate" in the city's governance. It culminated in a decoupling between the vetoes and the mayor on the part of his coalition, and linking customized on the part of "the opposition". The research comprising this work consisted of ethnographic observation of a parliamentary session on the morning of June 7, 2016, and short coexistence with officials of one of the offices, in addition to the concomitant analysis of documents originating from the "legislative process", that is, technical opinions of the Legislative Prosecutor's Office and the Executive Attorney's Office linked to the SME matter.

Keywords: Political anthropology, Governance, Municipal plan of education, City councilors, legislature. 


\section{INTRODUÇÃO}

Seja qual for a unidade da federação no Brasil, há diferentes planos que são corriqueiros e interdependentes para planejamento de gestões do Executivo a curto e longo prazos. Eles são criados pela Prefeitura e emendados e/ou votados pela Legislatura em vigor. Dentre esses estão mais reconhecidamente os planos orçamentários ${ }^{1}$, previstos pela Constituição Federal (CF) de 1988 para o exercício de um governo específico. Diferentemente dessas leis e do Plano Plurianual (PPA), há outros planos/leis que são divulgados como participativos na sua formulação pela legislativa federal. É o caso da política dos Planos de Educação, que contam atualmente com a obrigatoriedade de formulação e aplicação por estados e municípios. O contorno atual da política pública como criação, gestão e avaliação e de participação social na educação se materializou por meio de emenda à CF em 2009 durante o segundo governo do ex-Presidente Luís Inácio Lula da Silva (PT) (2007-2010) e, em maior escala, pela aprovação do Plano Nacional de Educação (PNE) no primeiro mandato de Dilma Rousseff (PT) (2011-2014).

A ideia de um plano de atuação enquanto lei para a educação circula no país desde a década de 1930, muito embora tenha sido tornado lei votada por legisladores federais apenas no final dos anos 1990 durante o segundo mandato do ex-Presidente Fernando Henrique Cardoso (1999-2003) (DERMEVAL, 2004). No entanto, sua forma atual é acompanhada de um discurso prático enquanto uma política pública e social em educação. Ela interliga obrigatoriamente todos os entes federativos, circunscrevendo, com isso, dinâmicas multilocalizadas que visam teoricamente interferir de maneira direta, e sem precedentes, em todas as leis sobre orçamentos de todos os níveis de Poder. Assim, conflui à articulação das noções nativas de poder de governar não apenas entre os legislativo e executivo, mas também entre participação popular, gestores e legisladores das cidades e da nação. Ao contrário de uma análi-

\footnotetext{
A Lei de Diretrizes Orçamentárias (LDO) é feita anualmente e orienta a formulação da Lei Orçamentária Anual (LOA), ambas seguindo o Plano Plurianual (PPA). De caráter quadrienal, o PPA não se refere apenas ao orçamento, mas prevê as políticas públicas, metas fiscais etc. e ultrapassa em um ano o Executivo seguinte.
} 
se que se preocupe com a avaliação de uma política pelos próprios funcionários de um setor do Estado, como fizeram Luiz Abreu e Frederico Silva (2012), este texto busca entender a formulação de um planejamento de políticas realizado por parlamentares.

Assim, o presente trabalho busca atender ao chamado de Laura Nader (1972), para quem a antropologia necessitaria dar um salto qualitativo ao se deter sobre o que chamara de os setores up da sociedade, isto é, os domínios de elites administrativas que compõem "o Estado" e decidem questões que afetam a população. Objetiva-se aqui mostrar a representação e as noções de poder de governar e política manejadas por parlamentares quando de sua participação no trâmite do Projeto de Lei 163/2015, posteriormente sancionado Lei 6.603/2016, que "Aprova o Plano Municipal de Educação" de Natal (20162026). Pretende-se analisar e descrever parte desse processo dinamizado na sessão que tratou dos vetos do Prefeito Carlos Eduardo Alves (PDT) às emendas dos Vereadores. No dia 7 de junho de 2016, o que poderia ser visto como uma sessão comum deu lugar a uma situação social corporificada na Câmara Municipal de Natal (CMN), uma vez que nela foram manifestadas aparentes confluências entre "situação" e "oposição" que trazem à análise problemáticas a considerar. Entendê-la dessa maneira permite examinar um fragmento da elaboração de uma política pública inédita na municipalidade (e, parcialmente no país, na forma da lei recente).

Inspirado em Ciméa Bevilaqua e Piero Leirner (2000), acompanhar a finalização da gestação dessa política possibilita ver a cidade de Natal a partir de dentro de sua burocracia estatal, levando a entender as relações que envolvem as decisões que interferem no acesso da população, principalmente crianças e jovens, à educação formal. Além de descrever o conjunto de políticas que a compõe para poder descrever modelos de "participação legislativa" na governança da cidade - termo êmico associado ao trabalho do vereador e ao exercício de sua representação. Enquanto é possível observar que um modo de democracia participativa seja evocado como um forte legitimador da Lei do Plano de Educação para todas as esferas, na argumentação de que apenas o conhecimento da "realidade local" propiciaria um "bom plano", a sua formulação entre 
Executivo e vereadores em Natal nem sempre esteve atenta ao indicado pelo documento-base elaborado pela equipe técnica sobre a educação municipal.

Isso nos leva a perceber o que Marcos Bezerra (2004) chamou de confronto entre novos e velhos modos de sociabilidade política, uma vez que a manutenção das decisões "participativas" na lei final não é certa e encontrou conflitos. Isto é, há um confronto comum no nosso arranjo político entre participação e representação. É no campo da representação que o que parece ter sido consensuado no campo da participação ganha modos de operacionalização distintos seguido de processos de negociação entre esses dois âmbitos da vida pública da política.

Tendo sido a penúltima capital a promulgar seu PME (1 de abril de 2016), $\mathrm{Natal}^{2}$ conta com uma população de cerca de 803.739 de pessoas (estimada em 885.180 habitantes para 2017) ${ }^{3}$ e de 551.364 de eleitores no último pleito (NATAL, 2015a). Esse cenário populacional leva a conceber a sua "representação política" por meio do cálculo por habitantes ${ }^{4}$ em 29 vereadores que se ocupam do legislativo (IBGE/CIDADES, 2010). Ao todo, foram apresentadas pelos parlamentares, em grupo ou sozinhos, 86 propostas de emendas ao PL do Plano Municipal enviado pelo Executivo. Contudo, apenas 34 foram aprovadas em plenário, tendo ainda 15 emendas sido retiradas pelos seus autores (e 5 prejudicadas) na sessão ordinária de 8 de fevereiro na CMN. As alterações se faziam na inclusão, alteração e exclusão de estratégias para alcance de metas propositivas, em matérias que vão desde o aumento do atendimento da população infantil em creches, a estrutura física de escolas, menção de gênero e sexualidade para capacitação de professores e carreira docente.

O recebimento dos onze vetos do Prefeito pela Câmara estabeleceu um conjunto de relações que coroam todo o trâmite do PME na cidade. Os funcionários da $\mathrm{CMN}$ e os vereadores evocaram, situação e oposição, os lugares do "legislativo" e do "executivo" na elaboração e execução de políticas públicas, de emendas, de projetos de lei e da própria gestão da cidade. Essa disputa

\footnotetext{
2 Natal foi fundada em 25 de dezembro de 1599, após a construção do Forte dos Reis Magos, destinado à ocupação colonial portuguesa.

3 Cf. IBGE/Cidades/Censo 2010. Disponível em: http://migre.me/upB2C. Acesso em: jul. 2016.

${ }_{4}$ Cf. http://migre.me/upBoq. Acesso em: jul. 2016.
} 
pela provisão ou, usando um termo de Bezerra (2004), pelo "monopólio" da governança e da representação política através de papéis separados foi materializado não apenas nas "falas" no plenário, mas nos pareceres técnicos das Comissões e da Procuradoria Legislativa, bem como nos discursos informais dos assessores. Isso tudo permite entrever noções locais de poder, política e de gestão da representação não apenas na ritualizada sessão parlamentar para derrubada dos vetos, mas em todo o percurso do PME e no tratamento da legislação federal como vetor usada para regular fronteiras entre tipos de relações no âmbito institucional.

A pesquisa realizada para esse trabalho compreendeu a realização de trabalho de campo por meio de visitas regulares que contou com observação participante da atuação de assessores de uma vereadora num dos gabinetes da Câmara ao longo de um mês, bem como da sessão legislativa de 7 de junho junto aos vereadores, assessores e outros funcionários. As impressões da imersão no campo partem e se dão em torno do começo da apreciação da vereança diante dos vetos do prefeito ao PME. Nesse sentido, o foco central da inserção etnográfica privilegiada para este artigo se refere à sessão junina de vetos como uma situação social, seguindo o método de análise conferido por Max Gluckman (2010). Esse tipo de tratamento metodológico implica observar um evento que afeta e envolve indivíduos localizados socialmente. Diferentemente de outras reuniões de votação, esse momento matutino alude não apenas às atividades imbuídas no protocolo de derrubada de vetos, mas expressa as relações e as noções de poder e governança que envolvem a Prefeitura e a Câmara dos Vereadores.

Minha entrada nesse espaço foi facilitada por relações pregressas com alguns assessores parlamentares. Mesmo sendo de acesso público, o contato prévio com dois assessores conhecidos de amigos foi crucial para que eu pudesse acompanhar os meandros envolvidos na construção do PME, e, principalmente, para a observação da sessão legislativa descrita. Enquanto ocupava uma das salas reservadas ao "público cidadão" para observar através do vidro que nos separava dos vereadores em plenária, fui confundido várias vezes como assessor. Atribuo isso principalmente a minha vestimenta "a cará- 
ter", acompanhando os subordinados diretos dos vereadores. Percebi ainda que "cidadãos" não eram presenças comuns na Câmara, dando aos presentes "bem-vestidos" ao olhar local uma distinção importante.

Enquanto um antropólogo que visitava a CME a primeira vez para um trabalho etnográfico, estive preocupado em acionar mais o modus operandi do etnógrafo do que o olhar do eleitor e cidadão. Segui, em parte, as orientações metodológicas de Karina Kuschnir (2007), para quem o antropólogo deveria tentar entender como os atores vivem a política e não deixar que seu desejo pela melhoria da democracia interfira na forma como se observa os agentes em campo. No entanto, isso não me impediu de lidar fortemente com minha posição de observador e de eleitor/cidadão que se preocupa com os rumos públicos da cidade, identidade dupla que constituiu elemento presente na descrição etnográfica/teórica aqui realizada.

Antes de entrar na descrição etnográfica é necessário uma incursão histórica institucional e política do plano de educação no Brasil, para então ser possível entrarmos na Câmara Municipal de Natal. Isto é, nas decisões tomadas entre suas paredes e na governança disputada pelos seus atores oficiais, e também os invisíveis, a partir da sessão legislativa que encerrou a tramitação do Plano de Educação natalense.

\section{O PLANO}

Márcio Bezerra (2012) já mostrou que a base eleitoral nos municípios é um espaço importante para a política nacional na manutenção da representação. Os congressistas federais agem na formulação de emendas orçamentárias cujo objetivo visa atender as demandas de obras urbanas na região de seus próprios apoios. Por sua vez, no nível micro dos vereadores, algo muito similar acontece nas mudanças feitas por eles nos projetos de lei de exclusividade do Executivo municipal e através de solicitações ${ }^{5}$ enviadas às secretarias. As

\footnotetext{
5 Os "requerimentos" são criados pelos vereadores e enviados às secretarias municipais para efetivar obras urbanas. Geralmente, correspondem às regiões onde estão suas bases eleitorais.
} 
emendas e os requerimentos ou "dispositivos parlamentares", como nomeia Bruno Silva (2014), comportam atitudes que demonstram "poder". A influência que intercede à oferta de obras e/ou políticas, embora não possibilite liberação financeira para ser encaminhada como no caso federal, cumpre a sua realização direta na região a que se pretende a obra ou ao público destinatário da política. No entanto, o que poderia ser chamado de "transposição" de um modelo de relação no âmbito nacional para os municípios é recente, guarda uma maior complexidade de diferenciação e corresponde, historicamente, a modificações institucionais recentes. Essas mudanças não se referem somente à nova figura do Prefeito, implantada apenas em 1930, mas por um conjunto de fatores que trouxeram maior autonomia e novos alcances dentro da lei para a gestão pela mão de uma municipalidade.

Segundo Maria Kerbauy (2005), essas mudanças institucionais datam desde a ditadura militar, com a reforma tributária em 1965, a instituição da Lei Orgânica em 1967 e a criação de regiões administrativas no interior do país. Isso estabeleceu maiores competências de coisa pública e a instituição da relação entre o legislativo e a figura do prefeito para a produção de leis. Ainda segundo a autora, a Constituição de 1988 resgatou essa autonomia e registrou um compartilhamento novo, em todos os níveis, de prerrogativas de execução e gestão de políticas públicas e sociais. Essas mudanças acarretaram importante impacto na vida dos cidadãos na forma como se relacionam com os setores do Estado.

A política do Plano de Educação, de ação territorial, tem reforçado a autonomia dos municípios, mas com maior interlocução no planejamento e execução com a União e com os Estados (e Distrito Federal). Notadamente, o Brasil deteve apenas três planos educacionais até hoje. Segundo Demerval Saviani (2004), a concretização de um Plano Nacional de Educação (PNE) no Brasil, com a inclusão de sua previsão na CF de 1934, seguiu a pressão popular encabeçada por um movimento social marcado pelo "Manifesto dos Pioneiros da Educação", lançado em 1932. No entanto, o primeiro plano brasileiro só foi formulado vinte e seis anos depois, sem força de lei e exclusivamente pelo Ministério da Educação em 1962. Posteriormente, em 1998, o segundo PNE 
procurava tornar-se lei e era apresentado pelo Deputado Federal Ivan Valente (PT) na Câmara dos Deputados, mas alterado profundamente pelo então Presidente Fernando Henrique Cardoso (VALENTE, 2001).

O terceiro PNE promulgado em 2015 contempla 20 metas e uma média de 6 a 10 estratégias cada uma, que devem ser seguidas pelas Prefeituras e Estados. Para isso o Ministério da Educação (MEC) concebeu um Caderno de Orientações (MEC, 2014), também feito no governo FHC, que visava indicar um conjunto de passos, instituições e noções que deviam estar presentes no processo de criação. Não há status de norma ou decreto nele evocado, mas reforça a legislação. Nesse manual há uma tentativa em conciliar a democracia participativa e a representativa. À acepção de "participação" pretende duas ideias distintas: uma ligada à representação da Câmara e do Executivo por meio de "atores governamentais", os quais seriam responsáveis por um documento-base resultado de um "diagnóstico" da situação educacional. Na dimensão "participativa", compreende-se, paradoxalmente, uma "sociedade civil" organizada por "representantes". Esses agentes seriam provenientes de escolas e universidades, movimentos sociais, instituições religiosas e outros grupos para "discussão democrática" das "necessidades locais".

O Fórum Municipal de Educação (FME) é erigido então como o criador inicial da política ao reunir com dimensão "técnica" e "democrática" todos esses especialistas e representantes dos setores do Estado e da população. A participação efetiva desses atores, segundo o Caderno do MEC, possibilitaria gerar uma "forte legitimação" para a revisão técnica e "discussão democrática" do documento-base. Partindo dessa referência avaliativa do município, o Prefeito cria um Projeto de Lei para, em seguida, passar ao crivo da Câmara dos Vereadores.

Com a sanção do Executivo, o plano adquire um formato particular. Inicialmente, apresenta-se uma lista de princípios básicos ${ }^{6}$ norteadores gerais e um "Anexo", nos quais estão descritas as "metas", objetivos a serem alcançados e as "estratégias", ações particulares que levarão às primeiras. Os planos mu-

O PNE dá o nome de "diretrizes", já o PPE/RN chama de "dimensões". No caso desse último, infere-se uma fraqueza discursiva do termo em relação aos PME e PNE. 
nicipais e estaduais devem contemplar o indicado pelo PNE, podendo ainda suprimir o que foi disposto nacionalmente caso o documento-base ateste que não contempla a região. É em torno da inserção de novas dimensões que signifiquem aumento de recursos que se encontram os principais conflitos no trâmite do PME em Natal, tanto entre parlamentares, como desses com o Prefeito.

Esse tipo de política "permanente" de Estado se refere a um processo de discussão no qual se cria e se modifica direitos, leis e normas que impactam diretrizes de acordo com as possibilidades de mudança. Fruto de uma administração pública localizada, elas são decididas nas secretarias e nas comissões das Câmaras, mais do que nas comissões técnicas anteriores à criação do projeto de lei pelo Prefeito. Nesse sentido é que no plano de educação nacional e nos municipais, no formato atual, propõem-se políticas sociais e públicas: reduzir as desigualdades sociais provenientes de diferentes acessos à educação formal (alfabetização e creches), provisão da carreira docente e o uso de recursos econômicos para provê-los. Baseia-se fortemente no discurso pelo desenvolvimento, do arranjo econômico.

A dimensão econômico-social é um grande denominador para inclusão e exclusão de metas e estratégias nos planos em educação. Como já pontuado por Anne Francis Okongwu e Joan Mencher (2000), o setor financeiro dos mercados tem atuado na diminuição dos governos em seu poder econômico e, direta ou indiretamente, no poder político daí proveniente. Okongwu e Mencher referem-se especificamente ao final dos anos 1990, quando o Brasil ocupava uma posição econômica diferente de hoje - nono lugar como potência ${ }^{7}$. Contudo a atuação do mercado na governança estatal tem se mostrado efetiva, principalmente com a influência decorrente desde os financiamentos eleitorais.

Seja qual for o nível, federal ou municipal, a política da educação em forma de plano compreende o alcance da população de forma progressiva à educação infantil, ao contrário do acesso ao ensino médio, fundamental e alfabetização que se pretendem universais. Em 2016, passados quase dois anos

Já tendo sido considerada a quinta e a sétima maior economia, hoje o país ocupa a $45^{\circ}$ posição econômica mundial, medição realizada pelo tamanho do PIB em 2017. Cf. <http://migre.me/upzrr> e <https:// g1.globo.com/economia/noticia/pib-do-brasil-fica-em-ultimo-lugar-em-ranking-com-45-paises.ghtml > 
da publicação da lei 13.005/2014 que instituiu o Plano Nacional de Educação (PNE), quase todos ${ }^{8}$ os 5.570 municípios brasileiros contavam com PMEs obrigatórios ${ }^{9}$ em vigor para o decênio 2015-2025. Com isso, criou-se uma política pública que se sobrepõe a planos orçamentários, principalmente pela recente vinculação dos seus recursos ao Produto Interno Bruto (PIB $)^{10}$ como uma das fontes principais, cuja imagem de "esforço nacional" é acionada.

Ao evocar Michel Foucault (2008), poderia ser dito que esta política pública em educação através dos planos-lei atuais, quando constitucionalmente detemos no país uma obrigatoriedade na aplicação pública de recursos e de diretrizes-chave, configura-se como marca, por excelência, do domínio da razão de uma governamentalidade. Isto é, um conjunto de reflexões, análises, procedimentos e técnicas que conformam o exercício do poder sobre uma população (FOUCAULT, 2008), ao se decidir "que problemas resolver primeiro" e "quem deixar de fora", quais recursos utilizar, qual nível estatal se responsabiliza por determinada faixa etária e modalidade de ensino, que conteúdos mínimos e qual a política para os profissionais. Esse tipo de prática específica de governança planejada, como poderia se classificar uma "política pública”, pode ser visualizada como uma ação econômico-social que visa ao emprego de recursos para atender a uma demanda de um setor estatal (TEIXEIRA; SOUZA LIMA, 2010).

Tanto a legislação como as orientações técnicas posicionam de maneira curta a "participação" dos vereadores como "aprovadores", ao se comparar a importância dada à inclusão da "sociedade civil" na formulação do PNE na ocasião da reunião do Fórum de Educação do município. As emendas, ao serem mencionadas nos manuais do MEC, são possibilidades corriqueiras, praxe democrática. No entanto, ao se propor e aprovar um projeto de lei que não é apenas a indicação do que pode ser feito em termos de política, mas uma discriminação detalhada de um plano de Estado, a Câmara de Natal envolveu

\footnotetext{
Atualmente apenas a cidade do Rio de Janeiro (RJ) encontra-se com o projeto de lei elaborado aguardando votação da Câmara de Vereadores. Todos os outros municípios brasileiros já finalizaram todo o processo institucional de criação dos Planos de Educação.

9 Anteriormente ao novo PNE, as formulações de planos de educação locais eram facultadas.

${ }^{10}$ Inciso acrescido pela Emenda Constitucional no ${ }^{\circ}$ 99, de 11/11/2009.
} 
seus atores em um conjunto de atividades que expressaram o embate pela governança da cidade, uma tensão em torno da disputa de poder entre funções e direitos do prefeito e dos vereadores. É nesse sentido que se pode falar em situação social, quando o evento observado pelo antropólogo extrapola cultural e estruturalmente os limites do que foi dramatizado pelos agentes em relação (GLUCKMAN, 2010).

\section{LUGARES DO/NO LEGISLATIVO: UMA SESSÃO ORDINÁRIA COMO SITUAÇÃO SOCIAL}

Quando vereadores natalenses reúnem-se em uma sessão de sua casa legislativa, onde os holofotes das câmeras estão posicionados para todos os lados, o que pode ser dito? Estariam todos a serviço da encenação e nós, majoritariamente afastados e passivos em "cegueira lógica", como têm descrito alguns filósofos ${ }^{11}$ ? Perceber que as tomadas de câmera são parte do modo como os agentes vivem a política possibilita ao analista uma leitura que não tome essa situação encerrada numa tentativa espúria de ludibriar eleitores futuros. A projeção pela TV Câmara torna-se um meio eficiente de se endereçar recados à população, a secretários municipais, aos colegas e ao próprio Prefeito. O letreiro eletrônico dentro do plenário, os televisores e caixas de som espalhados pelas antessalas e outras dependências da CMN ainda fazem circular o que acontece ali, de modo a efetivar práticas da política entre parlamentares.

Quando cheguei à Câmara de Natal no dia da sessão sobre os vetos e subi até a assembleia da casa, deparei com um dos elementos de grande destaque naquele lugar: uma câmera de vídeo posicionada de frente para a Mesa Diretora. Essa tomada possibilita um quadro amplo de toda a sala. Enquanto esperava a assessora parlamentar Maria em outro espaço "destinado à sociedade", separado apenas por uma parede de vidro do espaço da plenária, pude ver um grande telão disposto na parede à esquerda. Nele estavam os dados da

\footnotetext{
${ }^{11}$ Cf. Revista Cult, “A política como encenação”, edição 212, ano 10, maio de 2016.
} 
audiência pública ${ }^{12}$ que ali se realizava antes da sessão do dia. Enquanto vereadores falavam, dois cinegrafistas circulavam para tomar enquadramentos precisos. Como pude ouvir logo depois, a dinâmica da casa havia mudado recentemente. O expediente matutino separava a "primeira manhâ" para audiências às oito horas. Já às dez horas (até meio-dia) se reservava às reuniões de votação. Com o término da Audiência, eu era o único cidadão que assistiria a sessão que não era um funcionário da CMN ou jornalista.

Descrever uma sessão parte do cotidiano de uma Câmara apresenta alguns desafios ligados à enorme quantidade de "lugares" onde as coisas acontecem simultaneamente, a profusão de vereadores oradores e a multidão de objetos para apreciação (ofícios, requerimentos, projetos de lei etc.). Quando a "sessão dos vetos" finalmente se inicia, percebi que ela se subdivide em múltiplos momentos rituais e de espaços físicos, cujas salas do seu entorno são tomadas por debates interessados nas decisões dos vereadores. Juntariam-se a mim e ao assessor João, colega de gabinete de Maria, vários outros assessores técnicos e parlamentares. Os vereadores já iniciavam os discursos e Vanessa, técnica em educação que se juntara a nós e com a qual conversava sem apresentações, falava-me do trabalho árduo de formulação de emendas feitas pela Comissão de Educação e Cultura (CEC) ao PME. Esforço nem sempre recompensado, uma vez que, como me explica, os vereadores mudariam o que entendessem necessário. Os autorizadores da política, os vereadores, não estão isolados como tomadores de decisão, mas unem-se aos ouvintes, aos assessores e a todos que assistem as sessões e vivenciam o cotidiano na Câmara. Não há atores passivos e menos ou mais políticos do que outros no cenário do legislativo municipal. Seja Vanessa, João ou Maria, em diferentes níveis e gabinetes, todos compõem e fazem a política.

O plenário pouco a pouco ocupava-se de maior número de vereadores, muito embora se mantivessem em uma dispersão nítida com conversas paralelas ou aglomerados em uma sala localizada atrás da Mesa Diretora. Se algum assessor ou funcionário de copas desejasse entrar na assembleia, como vi

12 Audiência Pública sobre violências contra as mulheres em Natal/RN, autoria do Vereador Sandro Pimentel (PSOL). 
acontecer algumas vezes, era preciso trajar "roupas adequadas" (cobrindo os braços e pernas). Os seguranças de paletó e gravata impediam à porta a entrada de quem estivesse vestido de outro modo. Dentro do plenário, para qualquer "fala" (sentado à mesa comum), "discurso" (na tribuna) e apresentação de "requerimentos" tardios ou orais, era necessário pedir autorização ao Presidente. A expressão "pela ordem, senhor presidente" antecederia inúmeras vezes o pedido de esclarecimentos sobre o andamento da sessão; ou "com a palavra, senhor presidente", para mostrar opiniões sobre as matérias discutidas indo ou não à tribuna. Entre conversas de jornalistas e assessores que me rodeavam, tento prestar atenção ao que acontece entre "os políticos" e ao que é exibido pelo letreiro eletrônico que mostrava quantos vereadores se somavam presentes. Este era um dado muito importante, como aprendi com João, uma vez que é regimentalmente necessário que se forme o quórum com 21 vereadores para que se possa ter 15 votos à aprovação de qualquer "peça".

Contudo, o que descrevo corresponde a uma atividade bastante frequente na CMN, algo que acontece em média três vezes por semana. Que caráter de especialidade poderia ser evocado para algo tão costumeiro aos vereadores natalenses que, repetidas vezes, já discutiram, aprovaram ou rejeitaram outros vetos e projetos de lei? Em outras palavras, quais são as diferenças que a separam da reunião da semana anterior e daquela que a seguiu?

Uma sessão legislativa guarda um conjunto de características e etapas com forte apelo ritualístico. Há regras para entrada no plenário, para pedir autorização para falar ou discursar, tipos diversos de "peças" que se adéquam a atividades específicas (projeto de resolução, por exemplo, refere-se apenas a questões administrativas internas a $\mathrm{CMN}$ ), a gesticulação comum de olhar direto para as câmeras, tempo de oratória regulado, vestimentas etc. Ou seja, viver a prática da política na "casa" natalense implica seguir regras, um conjunto de práticas que objetivam alcançar significados atribuídos a ações e noções eficazes ao serem manejadas por determinados sujeitos. Por isso, Edmund Leach (1996) chega a definir ritos como "afirmações em ação", com as quais indivíduos explicitam modelos sociais que descrevem idealmente o mundo de suas relações. O autor ainda afirma que ética e estética não se separam, o que 
nos leva a perceber que o caráter formal dos vereadores para demonstrar rigor ético se realiza de maneira indissociável de sua estética expressiva. Assim, a máxima "pela ordem" do legislador afirma e cria uma estética ética-moral.

Quando Mariza Peirano (2002, p. 35) argumenta uma proposta de abordagem antropológica que retome uma análise de rituais clássica para examinar eventos contemporâneos, ela refere-se a fenômenos não rotineiros e específicos. Mesmo que a dita sessão seja, em seu formato, corriqueira, o "conteúdo" que apresenta formaliza e dinamiza um conjunto de práticas, relações e ideias que a extrapolam e que estão ali sendo amplificadas. Enquanto um evento atípico, crítico (e de crítica) ao se tratar de vetos a emendas ao Plano Municipal de Educação, a sessão trouxe à baila relações entre vereadores e prefeito de modo inusitado, em que a própria base governista parece acompanhar a oposição. Enquanto um evento, a sessão esclarece o repertório social e seus mecanismos de consolidação. Evidencia, ainda, que a aliança entre situação e oposição é apenas superficial, elas continuam em lados diferentes.

Diferentemente de Peirano, Max Gluckman (2010) concebe um método para tratar os eventos observados pelos antropólogos, definidos por ele como "situação social". Na abordagem da autora, procura-se um "evento ruptura" que performatize o que a sociedade mantém "parado" e que entra em "erupção" Já em Gluckman estuda-se o comportamento de indivíduos como parte de uma comunidade, aliando o que compõe um "sistema subjacente de relações” combinado de estrutura social, meio físico e disposição fisiológica dos indivíduos. Assim, se em Peirano é possível algum nível de probabilidade no tipo de evento analisado, Gluckman (2010, p. 257) foca em determinar que há partes que "não são planejadas", mas seguem a estrutura social.

Quando Gluckman faz uso de seu método ao analisar a inauguração de uma ponte na Zululândia na África do Sul, ele está preocupado em descrever um equilíbrio entre partes da estrutura para a manutenção da coesão social - negros zulus e brancos. Entretanto, ao contrário do núcleo de antropólogos britânicos estruturalistas, o autor concebe essa coerência entre as posições não apenas por meio de harmonias, mas com conflitos e descontinuidades. Atrela-se ainda o que Lilian Chaves (2016) chamou de teoria perver- 
sa, uma vez que o autor entende que o domínio dos brancos africanos sobre os zulus é visto como uma necessidade para essa coesão. Era o que garantia a ideia de uma comunidade zulu-europeia.

No entanto estou detendo-me aqui a um evento que não é de alcance geral pela maioria dos cidadãos do município a que corresponde, algo que está mais próximo da Audiência Pública descrita por José Lopes (2004) para implantação de uma Usina Nuclear em Angra dos Reis/RJ e, da experiência de orçamento participativo entre niteroienses, analisada por Marcos Bezerra (2004). Apesar das decisões dos vereadores natalenses na Câmara repercutir na vida cotidiana dos seus conterrâneos, a votação dos vetos pode ser vista como um nicho de vivência da política por atores determinados. Desse modo, seus projetos de lei, emendas e relações com os setores do Executivo não estão isolados de uma gama de dimensões estatais em outros planos e com as suas bases que representam politicamente. Mesmo assim, os vereadores estão a todo tempo nesse evento corriqueiro, expressivo das experiências políticas que dinamizam no município, situações criadoras de realidades, reclamando lugares próprios de poder para uma atuação e intervenção na governança da municipalidade.

\section{PARA QUE SERVE UM VEREADOR? "INDIVÍDUOS", "PESSOAS" E "PARTICIPAÇÕES LEGISLATIVAS"}

Quando tento prestar mais atenção no que se passa em plenário, entre as conversas dos assessores que parecem me impedir de ouvir qualquer coisa além deles mesmos, eis que o presidente da Câmara de Natal, Vereador Franklin Capistrano (PSB) já tinha iniciado os trabalhos, passando a palavra ao Vereador Hugo Manso (PT) para leitura da Ata da sessão anterior. Além desse início, poder-se-ia dividir a sessão dos vetos em mais cinco períodos diferentes: 1) “ordem do dia", no momento em que o secretário leu a pauta a ser votada, os ofícios recebidos e requerimentos às secretarias enviados pelos legisladores; 2) votação e discussão dos processos em pauta, a qual se deu sobre a derrubada de quatro vetos do Prefeito ao PL do PME; 3) aprovação dos requerimentos já 
apresentados; 4) "pequeno expediente", separado para discursos em "tribuna" acerca de assuntos do interesse do vereador; 5) e "horário de lideranças", semelhante ao anterior, mas apenas aos líderes de bancadas, governo e partidos.

No segundo momento da sessão, o qual ainda subdivido em "discussão", "declaração de voto" e "votação", o presidente Franklin Capistrano lembra que começariam a votar a derrubada ou não de vetos a Lei 6.063/2016 (antes PL n. 163/16) que "aprova o Plano Municipal de Educação de Natal". São, ao todo, como lembraria a Vereadora Eleica Bezerra (PSL) mais tarde, onze vetos a artigos, metas ou estratégias. No entanto, entrariam apenas quatro ${ }^{13}$ desses processos na sessão junina, uma vez que três deles estão sendo analisados pela Comissão de Constituição e Justiça (CCJ) e quatro com a atenção da Procuradoria Legislativa (PL-CMN).

Para que comecem as “discussões” que precedem a "votação", Capistrano apresenta o Processo n. 015/2016, de autoria do Chefe do Executivo Municipal, referente ao parecer técnico da Procuradoria-Geral do Município (PGM) que justifica o veto do Prefeito sobre o Inciso V do art. 4 do PL n. 163/2016 do PME. A emenda vetada, proposta pela Comissão de Educação e Cultura (CEC), cria um Conselho Municipal dentro da CEC para controlar os usos do FUNDEB $^{14}$ para atender as metas e estratégias do Plano pelo Executivo. As principais razões do veto parcial podem ser vistas nos excertos da Mensagem n. 014/2016 enviado a CMN pela Prefeitura:

Segundo o art. $5^{\circ}$. Da Lei Municipal nº. 5.785/2005 (publicada no DOM em 17/05/2005, p. 01), o indigitado Conselho somente detém competência para fiscalizar os recursos do FUNDEB; e nenhuma outra atribuição a mais. Com essa alteração, o legislador local ampliou o plexo de encargos do Conselho - sem que o referido órgão colegiado fosse objeto do presente projeto de lei.

\footnotetext{
13 Como pode-se observar adiante, a sessão acaba por votar apenas dois desses vetos. Os outros passam para a sessão seguinte no dia $08 / 08$, que também foram derrubados. Esses últimos referem-se a duas estratégias inseridas por emendas coletivas. São: 18.10) assegura benefícios de auxílio alimentação e transporte aos trabalhadores em educação, e 20.4) assegura os fundos para educação em 30\% do orçamento municipal, complementado ainda para atingir $5 \%$ do PIB de Natal.

${ }^{14}$ O Fundo de Manutenção e Desenvolvimento da Educação Básica e de Valorização dos Profissionais da Educação (FUNDEB) trata-se de recursos para uso exclusivo na educação pública em todos os níveis.
} 
Infelizmente a emenda parlamentar aprovada é formalmente inconstitucional. Isso porque a iniciativa legislativa - versando sobre a alteração de atribuições de órgão municipal de composição colegiada (juntamente com as respectivas competências) - é de autoria exclusiva do Prefeito de Natal, nos termos do art. 21, IX, e art. 29, $\$ 1^{\circ}$, ambos da Lei Orgânica Municipal.

[...]. Quando a Casa Legislativa aprovou emenda, acrescentando novas atribuições ao Conselho do FUNDEB [...], o novel inciso V do art. $4^{\circ}$. Do projeto usurpou a iniciativa privativa do Chefe do Executivo para legislar sobre atribuições do órgão colegiados da Prefeitura (PREFEITURA DE NATAL, 2016).

Os vereadores ao apreciarem esse veto poderiam seguir os juízos da CCJ para manter a restrição ou o parecer da Procuradoria da Câmara, que é a favor da queda dos argumentos do Executivo. Contudo, quando Capistrano anuncia a posição da CCJ, o Vereador Felipe Alves (PMDB) lembra que houve um engano da relatora, a Vereadora Eudiane Macedo (PHS), que não estava presente. Na verdade, o parecer da Comissão da qual ele é presidente seria contrário ao Prefeito. Há, então, uma tentativa de retirar o processo de pauta, porque se atribui à vereadora um erro por desinteresse em fazer seu relatório. Mas o Vereador Sandro Pimentel (PSOL), considerando não saber as "reais razões" do parecer de Macedo, sugere que se siga o debate, pedindo inscrição para falar. Quando sobe à tribuna, o parlamentar discursa calorosamente sobre como os vetos "sem propósito" da Prefeitura se apresentam como impeditivos ao exercício do "papel" e da "missão" da CMN. Ele pergunta se fizeram algo de errado ao preverem um Conselho Municipal de Acompanhamento e Controle Social do FUNDEB.

Que crime tem nisso? Quanto mais organizações tiverem querendo ou imbuídas no propósito de acompanhar e monitorar a execução prática do PME, para que o PME não seja apenas uma peça teórica, mas que ela vá para a prática, quanto mais, melhor. Carlos Eduardo alega que a Câmara tá criando uma atribuição para o Conselho do FUNDEB. Se o projeto fosse de iniciativa dessa casa, não poderia. Mas o projeto é de iniciativa do Executivo. Cabe a Câmara constituir emendas às peças 
que forem do Executivo, porque se não for assim nós vamos fazer o que aqui, hein? $\mathrm{O}$ prefeito Carlos Eduardo vai mandar um projeto $\mathrm{e}$ a gente vai dizer sim ou não? A gente nem pode aprimorar, não pode melhorar? Nosso papel é esse. E a Câmara melhorou! A Câmara atendeu a uma demanda que discutiu por várias vezes com sua equipe, sua estrutura de assessores, a Comissão de Educação e, a Câmara sabiamente acolheu esta emenda e aprovou à unanimidade de votos. O que é que o prefeito Carlos Eduardo faz, que não gosta de transparência? Vetou! (Fala de Sandro Pimentel).

Tanto na oratória de Pimentel como na de outros vereadores, o domínio da legislação dá o tom para mostrar os vazios ou validades das argumentações de um idioma jurídico para manter ou não as emendas. Ler normas técnicas, regulamentos e leis em púlpito dá notoriedade ao poder que desempenham de "legislar e fiscalizar". É com essa imagem que atrelam o "papel" da Câmara enquanto corpo unido de legisladores. O vereador pelo PSOL, oposição ao governo, encerra seu discurso clamando aos demais para que o veto não deixe de ser derrubado e abre uma cadeia de falas que constroem na figura do vereador a responsabilidade e o mérito de impedir que o Plano Municipal de Educação se torne algo "fictício".

Então não é possível que esta casa não derrube este veto. Quero crer que vai derrubar [...] e que nós vamos aumentar sim mais um órgão fiscalizador para fazer com que o PME não seja uma peça fictícia, não seja uma peça no papel, mas que acima de tudo que a população espera e que nós esperamos, é que o PME vá para prática com seus avanços que nós conseguimos obter aqui através e uma discussão muito qualificada na CMN. Esse nosso voto antecipado contrário ao veto, sr. Presidente (Fala de Sandro Pimentel).

Os vetos entram em cena como previsão de "má gestão" na qual a formulação e avaliação da política pública se torna o epicentro da "boa gestão" anunciada. Mesmo que colocar em prática a lei do PME caiba à Secretaria $\mathrm{Mu}$ nicipal de Educação, esses atores entendem ser sua formatação normativa irrepreensível para que a "realidade de Natal" melhore em índices de desenvolvimento. $\mathrm{O}$ vereador Hugo Manso (PT), que toma a tribuna logo em segui- 
da, acusa o Prefeito de não procurar o diálogo com a CMN antes de "meter a caneta", atos e impedimentos que se multiplicam inadvertidamente em vários outros PLs. Para Manso, se o Prefeito procurasse a CMN para uma conversa explicativa seria o ideal à boa formulação da política. Outros vereadores aludem ao mesmo nível de descontentamento com o que veem como "justificativas fracas" dos pareceres da PGM, inclusive parlamentares ligados em apoio ao Prefeito. No entanto, o vereador Raniere Barbosa (PDT), líder do governo na casa, os atribui a erros da Procuradoria-Geral do Município e não ao Prefeito. Apresentando seu voto, diz em direção ao Presidente:

Acho que a Procuradoria do Município errou que muitos dos vetos que estão aqui eu mesmo vou votar contrário, já estou antecipando, porque votei favorável discutido com a Procuradoria da Câmara, discutido com a assessoria técnica do município, fomos orientados pela Secretaria de Educação e depois vir dizendo que estava contrário? [...]. Então, me desculpe, tem algumas contradições. Vamos zelar sim, não por uma independência de poderes, mas sim pela transparência que, inclusive, é uma bandeira do Prefeito Carlos Eduardo e que ele defende isso. Se a PGM entendeu, não comunicou ao Prefeito porque garanto que se o prefeito Carlos Eduardo tivesse esse conhecimento ele era o primeiro a aprovar. Mas me desculpe a PGM que errou, errou e erra em não buscar uma interlocução com o poder legislativo antes de apresentar o veto [...]. (Fala de Raniere Barbosa).

Outros parlamentares que compõem a base do Executivo, como Felipe Alves, Júlia Arruda e Júlio Protásio (PDT), seguem o líder e “declaram voto" contrário. A Vereadora Amanda Gurgel (PSTU), olhando para a câmera de vídeo quando sobe a tribuna, lembra que é atribuição dos vereadores fiscalizar os usos dos recursos públicos e que o FUNDEB já é entendido como objeto de regulação contínua na legislação. No final da discussão há um reconhecimento de que faltou análise acurada do Prefeito (ou da PGM) sobre as emendas que rejeitou e de uma inaptidão em gerenciar a coisa pública. Fernando Lucena (PT), por exemplo, chega a chamá-lo de “inconsequente", e de ligar o trabalho da PGM ao mal feito: "parecer sem pé nem cabeça”. Nesse momento, uma glorificação da Procuradoria da casa é realizada, pois, segundo Luce- 
na, os advogados da CMN "trabalham melhor e até recebem menos" - "deveriam ganhar igual".

Toda essa dinâmica sobre a existência ou não de "vício de iniciativa", isto é, se a Câmara havia legislado em peças exclusivas do Executivo, leva à votação eletrônica que derruba o veto por 19 votos a favor, e nenhum contrário. Para isso, os "vereadores da situação" engajam-se em não ligar diretamente o nome do prefeito aos vetos, mas criam para eles uma ideia de impessoalidade ao separarem o objeto do seu autor. Já os legisladores “da oposição” realizam o contrário, avocando um vínculo irredutível. Cenário expressivo, portanto, de alianças e segmentaridade na relação entre Executivo-Legislativo não são objetos simples de percepção, explicação e experiência dos atores.

Realiza-se, pelos oradores, a construção do prefeito enquanto pessoa, nos termos de Roberto Da Matta (1997). Mas isso não se constitui de modo a individualizar (DUMONT, 1985) os vereadores contrários à base do Executivo. Não há “indivíduos” concretos na votação sobre vetos, mas a expressão de um "sistema de pessoas", embora fissurado. Nele, onde todos são "gente", para usar um termo de Da Matta (1997, p. 232), sustenta-se um universo social segmentado em grupos que hierarquizam as relações. $\mathrm{Na}$ medida em que o prefeito ultrapassa o limite da quantidade de vetos aceitáveis, ele corre o risco de ser dirimido de seu caráter de superpessoa, ou seja, o trabalho de quem não pode ser atacado - pela sua própria base.

A ciência política tem se preocupado com a construção de apoios políticos e com análises de discussões, votações e meandros do "processo legislativo" e decisório. O Executivo, segundo esses autores, teria "recursos de poder que limitam a produção" dos vereadores, contribuindo para fazê-los "perder a capacidade" de suas atribuições. Para isso acionam o que chamam de "taxa de sucesso" para medir o "grau de dominância" (SILVA, 2014, p. 213). Através de uma média entre projetos aprovados e apresentados, ter-se-ia a aritmética que comprovaria a "real” origem das decisões. Entretanto, agrupar os projetos de lei e emendas diante de uma relação de dominação de outro setor pode ofuscar o modo como os vereadores significam a política. 
É por isso que Karina Kuschnir (2007) chama atenção à abordagem e à classificação sociológica desse universo, uma vez que abordar a política implica observar como os atores a compreendem e a experimentam, como a significam e praticam. Nesse sentido, chamar nossas práticas políticas de "coronelistas", "mandonistas" e "clientelistas", segundo a autora, é circunscrevê-las como práticas inferiores em relação às semelhanças de outros países. Em oposição à base interpretativa que vê o clientelismo como sintoma de subdesenvolvimento, atraso político e não alinhado aos princípios democráticos, Kuschnir (2007, p. 164) propõe vê-lo como "expressão de valores culturais que privilegiam as relações sociais entre pessoas" e não entre "indivíduos". Mas essas relações, no contexto natalense, não se dão somente entre parlamentares eleitos (candidatos futuros) e cidadãos (eleitores em potencial), mas também entre o que Da Matta (1997) chamou redundantemente de pessoas-instituições, ou seja, os setores estatais enquanto disputam o gerenciamento dos negócios do Município de Natal.

\section{"O CALOR DE NATAL ESTÁ AUMENTANDO": POLÍTICAS DE TEMPERATURA E VETOS POLÍTICOS}

Depois que se manteve a criação do "Conselho do FUNDEB" na Câmara, o horário já estava bastante avançado. Entramos nas doze horas, a fome começava a apertar e "ainda faltam três vetos" para serem discutidos e votados, como o Vereador Sandro Pimentel lembrou a Mesa Diretora, que agora era presidida pelo Vereador Felipe Alves - mudança feita sem grande aviso formal pelo presidente anterior. Depois de um debate, Alves decide manter, por enquanto, apenas o próximo veto. "Se necessário, pedimos prorrogação", diz. O processo n. 019/2016 que anuncia se refere à rejeição do Prefeito à inserção de uma nova Estratégia para a Meta 7, através da qual se promoverá a "climatização progressiva", ao longo do decênio, de todas as salas das "unidades de ensino". A discussão que recomeça repete a empolgação da anterior pelos vereadores de oposição e o apoio da "base do governo" orientada pelo Vereador Raniere. 
Segundo parecer que nega a emenda, teria sido criada "novel obrigação" que "provoca uma elevação excessiva nos gastos de custeio com o ensino regular, cujo dispêndio não constou na proposição original apresentada" (NATAL, 2016, p. 1-2). No entanto, os vereadores não aceitam esses argumentos, respondendo que a Secretaria Municipal de Educação (SME) de Natal já tem obrigação de melhorar a infraestrutura das escolas. Seria algo lógico, de acordo com o Vereador Marcos Antônio (PSOL), que qualquer estrutura física construída seja pensada para propiciar o bom desenvolvimento das atividades que ali irão acontecer. Essa fala foi reforçada pelos pareceres técnicos da Procuradoria Legislativa que orientam a CMN a derrubar a suspensão, uma vez que não teriam sido criados "direitos nem deveres" para a SME. O Parecer Processo n. 19/2016 expõe inicialmente a estratégia incluída sobre a climatização, para posteriormente apresentar as razões do veto do Prefeito e argumentos contrários. Alguns de seus trechos que fundamentam a orientação para derrubada do veto são elucidativos:

Percebe-se o alegado quando visualizamos sistematicamente o PME. O item 7.31 está inserido dentro das estratégias da Meta 07 do anexo do PME. Ou seja, a climatização das salas de aula é uma estratégia a ser considerada pelo Gestor quando à implementação e fomento da qualidade da educação básica em todas as etapas e modalidades

[...]. A imperatividade da estratégia vetada depende da conveniência e oportunidade da Administração em realizar a climatização das salas de aula ao longo da execução do PME como estratégia para se fomentar a qualidade da educação básica, o que decorre da vontade exclusiva do Chefe do Executivo Municipal.

[...]. Não se trata a emenda de matéria adstrita à criação de uma novel obrigação, atribuição ou estruturação à Prefeitura ou à Secretaria Municipal de Educação.

[...]. Assim, em virtude desta prevalência do Plano de Educação sobre as normas orçamentárias, essas ultimas deverão se amoldar para garantir a execução e cumprimento do PME, e não o contrário como insistentemente sustenta o Poder Executivo. 
A oratória dos vereadores segue para corroborar esses contra-argumentos e ainda para afirmar a qualidade pedagógica de um ar-condicionado quando usado na região "calorenta" de Natal. A Vereadora Amanda Gurgel (PSTU) é a primeira a subir à tribuna e procura explicar a urgência da refrigeração e a facilidade de sua aplicação. Suas palavras também dão início a vários outros discursos que pontuam a obviedade do avanço tecnológico que deixará esse tipo de aparelho elétrico de condicionamento do ar ultrapassado no futuro. A vereadora justifica a amenização do calor como forma de aumentar o Índice de Desenvolvimento da Educação Básica (IDEB) no município, que conta com "atraso de aprendizagem".

Como a educação infantil e o ensino fundamental são as atividades escolares obrigatórias a serem ofertadas pelos municípios brasileiros, a preocupação de um Plano Municipal de Educação cai sobremaneiramente na escolarização de crianças e adolescentes. O IDEB é resultado de uma prova aplicada nacionalmente a todos os estudantes e visa saber a aprendizagem em leitura, escrita e matemática. Segundo o diagnóstico do documento-base feito pelo Fórum Municipal de Natal, as médias natalenses estão abaixo das notas nacionais e estaduais em até $6 \%$.

Com a exceção do aumento de uso de tecnologias e do funcionamento regular de salas de "recursos multifuncionais", ou seja, de informática, nenhuma das estratégias apontadas pelo Fórum para melhoria nos índices prevê mudanças na estrutura física das escolas, como a inclusão de ar refrigerado ou projetos arquitetônicos que repensem a circulação do ar natural. Isso é seguido pelas metas presentes no Projeto de Lei enviado pela Prefeitura a Câmara de Natal, o que leva os vereadores, seja da oposição ou não, a atrelar a temperatura na sala à "boa educação pública".

O "trabalho trabalhoso de aprender", segundo a Vereadora Eleica Bezerra, não pode deixar de contar com a refrigeração de ambiente, porque o calor não permite aos alunos e professores o pensamento tranquilo. Ela chama de "blá-blá-blá" os argumentos da Procuradoria do Executivo, que não tratou com o devido cuidado de uma "ideia tão séria". "Foram 13 páginas, que eu acho que se gastou muito papel, muito material, 13 páginas, que aqui me 
parece, com todo respeito [...], que eu acho que aqui teve algum estagiário de Direito fazendo o chamado copiar e colar, entendeu?!". Outros parlamentares, como Júlia Arruda e Fernando Lucena, discursam que os alunos pobres de escolas públicas estão em grande desvantagem se relacionados com alunos que têm escolas particulares com ar condicionado. Lucena coloca ainda esse aparelho como mais importante que computadores, uma vez que "o calor tá aumentando" na cidade.

Essa preocupação dos legisladores com a interferência do clima ${ }^{15}$ da cidade na qualidade do ensino contribui para a formulação de uma minipolítica dentro da política maior do Plano de Educação, objetivando alcançar os corpos dos alunos e dos professores "que suam" no lugar de aprender e ensinar. A Vereadora Amanda descreve ainda que alunos "rasgam páginas de cadernos para se abanarem" e "professores sofrem de quedas de pressão" arterial devido ao forte calor natalense. O Vereador Sandro Pimentel completa ser a política do Prefeito não se preocupar com isso:

Para o Prefeito Carlos Eduardo, as crianças têm que torrar mesmo nas salas de aula. Torrar! Quanto mais torram, melhor, né?! É essa a visão que o gestor do Município de Natal tem. Quando a Câmara tenta aperfeiçoar, melhorar, oferecer condições e qualidade na educação, então o prefeito logo veta, porque não é interesse que as crianças, a base do processo educacional, tenha qualidade de ensino (fala de Sandro Pimentel).

Seguindo os vereadores da oposição, Raniere Barboza e Júlio Protásio reconhecem ser a "boa temperatura" essencial à prática docente e ao processo de ensino-aprendizagem, o que discursam sem ligar diretamente a figura do Prefeito ao veto. Algo já corporificado no debate anterior. Raniere declara que se vê obrigado a derrubar o veto porque "consensos" firmados com a própria SME antecederam a votação da emenda da refrigeração, uma vez que seu trabalho na formulação do PME foi desconsiderado. Esse argumento também foi levantado pelo Vereador George Câ-

\footnotetext{
15 O clima de Natal é "tropical chuvoso com verão seco", com uma temperatura média de $30^{\circ} \mathrm{C}$ e a maior taxa de insolação das capitais brasileiras, segundo o Instituto Nacional de Meteorologia.
} 
mara (PCdoB), que se estranha com a diferença de uma posição consensual da SME antes da votação.

Enquanto exercício do poder em contextos institucionais, a governança é definida por Carla Teixeira e Antônio Souza Lima (2010) como uma gestão política de assuntos e recursos da coletividade. Com a formulação de ações ou na avaliação periódica da Comissão de Educação não previstas pelo Prefeito Carlos Eduardo, os vereadores natalenses reclamaram participação nos negócios que envolvem a receita do Município, portanto, colocando-se como guardas das políticas que compõem o PME. A "boa governança” seria então vista como assegurada com o trabalho parlamentar.

As práticas legislativas são comumente ligadas a processos eleitorais, a rituais políticos, à expressão ou manutenção da representação (PALMEIRA; GOLDMAN, 1996; BEZERRA, 2012; 2004) principalmente devido à complexidade do voto e ao grande destaque da função criadora de leis e fiscalizadora de prefeitos, governadores ou presidentes. Mas a recente implantação de lei de plano educacional no município de Natal deu novos contornos amplificadores e inseriu novos autores com maior poder decisório em tecnologias de governo, diferentemente da imagem do gestor único.

Michel Foucault $(2008 ; 2012 b ; 1988)$, ao discutir a ausência de naturalidade para a junção entre Estado e Governo, mostrou que essa ideia corresponde a um processo histórico que modificou a relação do Estado diante das pessoas. Com o abandono gradual da concepção do Estado soberano sobre súditos dispersos que respondiam a pais e ao rei, dar-se-ia lugar a uma política de fazer viver e impedir a morte. Uma biopolítica em que as características biológicas do corpo humano entram como matéria de poder, principalmente através de tecnologias de registro e controle (FOUCAULT, 1988). O corpo do professor, alterado pela queda de pressão arterial, e os alunos que danificam seus materiais de aprendizagem são, portanto, nessa minipolítica de refrigeração parlamentar, a ação de uma biopolítica preocupada com a manutenção da saúde das pessoas.

A Câmara e o Executivo de Natal acabam por compreender duas políticas diferentes para a educação no tocante às condições climáticas. A primei- 
ra tratando discursivamente na oratória e na formulação de emendas do clima como variável que atrapalha o "bom ensino", e a segunda erigindo razões de incapacidade orçamentária para o que considera "gasto excessivo" da climatização. Nessa argumentação do Prefeito, a compra de refrigeradores de ar criaria uma despesa que não fora prevista do Plano Plurianual de seu governo nem na Lei Orçamentária Anual vigente. No entanto, isso é amplamente ojerizado pelos vereadores, seja para chamar a diminuição do calor nas salas de aula como de investimento ou obviedade, seja para lembrar que os próprios Planos de Educação Nacional e Municipal estabeleçam que as metas e estratégias tenham prevalência sobre todas as peças orçamentárias.

Diante do que consideram como vetos inadvertidos, "blá-blá-blá", "sem pé nem cabeça", "erro jurídico", "equívoco" ou não priorização de destinação de receita para a educação pública, os legisladores acabam por construí-los como ausentes de técnica ou cheios de razões políticas com o intuito de governar contra a população. Sandro Pimentel, no final do seu discurso, defende que:

O problema é que o prefeito de Natal, ele tenta inventar artimanhas para tentar vetar algo que era pra melhorar a educação do Município de Natal. Então chega a ser bizarro, sabe, esses vetos. As justificativas desses vetos que chegam aqui na Câmara chegam a ser bizarras. E ele levanta cada factoide aqui que é impressionante (gala de Sandro Pimentel).

A Vereadora Amanda, seguindo Pimentel, defende que bastaria um planejamento do prefeito, refrigerando catorze escolas por ano para concluir o decênio com todas as unidades em boas condições para o ensino. O Vereador Lucena, por sua vez, grita em tribuna que o veto do prefeito é ideológico, político, que não se preocupa com os filhos dos pobres. Já o Vereador Raniere Barbosa entende o veto como confuso ou sem sentido, devido justamente ao consenso junto à SME e no debate no plenário que ele e a base governista seguiram para votarem as emendas.

Passados os discursos na tribuna, o presidente que agora retorna para o vereador Capistrano convoca à votação, anunciando outra vez a una- 
nimidade que rejeita a suspensão do Executivo para a emenda "do ar condicionado". Dezoito votos computados a favor, os parlamentares continuam a sessão para a quarta e quinta etapas, conforme descrevi anteriormente o pequeno expediente e o horário de lideranças. Nesse momento, quase todos os vereadores saem do plenário, ficando apenas a Mesa Diretora e os inscritos para falas no púlpito. As antessalas de impressa e assessores também se esvaziam, seguindo para a sala da TV Câmara ou para gabinetes. Ao que me pareceu, as falas dos que ficaram, iniciadas pelo vereador Marcos Antônio, compreendem os mais variados assuntos, nenhum ligado ao PME. Com o término do horário de lideranças, que repete o período anterior, vejo alguns vereadores dando entrevistas para repórteres da TV Câmara sobre a inusitada derrubada de vetos. É nesse momento que me volto para a saída e, conversando com alguns assessores, me despeço. A câmara parece agora mais tranquila.

\section{CONSIDERAÇÕES FINAIS}

Ao centralizar a observação de uma sessão ordinária numa Câmara Municipal para este trabalho, fui confrontado com a impressão comum, bastante pessimista, de que os vereadores agem sempre por interesses escusos, que nunca dizem a verdade (TEIXEIRA, 2014). Seriam políticos profissionais que ressurgem a cada quatro anos para "pedir votos" na época de visita à cabine de votação, quando os eleitores "perdem o valor" após votarem, como diria minha avó. Considerando a (des)importância geral, a praticidade para a efetivação de obras urbanas e a ideia de corrupção popularmente atreladas à figura do vereador, suas atividades e sociabilidades políticas não estão dissociadas das relações que conformam as bases eleitorais e de manutenção da representação. Os legisladores municipais, tomados por cientistas políticos como a "unidade mais básica da vida e da experiência política dos cidadãos e agentes públicos" (ROCHA; KERBAUY, 2014), estão inseridos em contextos nos quais as práticas de poder não se reduzem à máquina estatal. 
Ao tomar metodologicamente a sessão de 7 de junho de 2016 como uma situação social, nos termos de Gluckman, foi possível entrever as manifestações daquelas que são as noções de participação legislativa manejadas pelos vereadores. Pensando a formulação do Plano Municipal de Educação de Natal como a primeira política de educação em plano-lei de grande porte da capital potiguar, foi possível entender meandros de construção de ações concretas que afetam mais de 60 mil crianças e adolescentes que constituem a parte da população diretamente afetada pela gestão da educação municipal. Ao invés de uma relação Executivo-Legislativo, unidade privilegiada pela ciência política para entender os processos decisórios nos plenários dos parlamentos, é possível que nem um polo nem o outro apresentem unidade de setores. A Secretaria Municipal de Educação e o Gabinete do Prefeito nem sempre estiveram na mesma sintonia, nem mesmo os vereadores.

No entanto, a vivência e os significados atribuídos ao que se entende como política pelos vereadores reclama uma maior participação legislativa na gestão de Natal, impedida pelos vetos "sem fundamentos" do Prefeito. A governança nesse meandro torna-se objetivo coletivo de decisão e objeto principal de conflitos, em que uma possível "taxa de sucesso" para medir as decisões de parlamentares atribuída por politicólogos não poderia alcançar compreender. Há "concessões" e "consensos" que são erigidos pelos vereadores quando votam e emendam PLs criados pelo Gabinete do Prefeito, como o PME, não permitindo uma visão de "origem da decisão" na formulação de políticas e leis de modo uniforme.

\section{REFERÊNCIAS}

1. ABREU, Luiz; SILVA, Frederico. Levando a sério o que nos dizem: notas sobre narrativas e avaliação nas políticas públicas. Textos para discussão, n. 1730. Rio de Janeiro: IPEA, 2012.

2. BEVILAQUA, Ciméa; LEIRNER, Piero C. Notas sobre a análise antropológica de setores do Estado brasileiro. Revista Antropologia, v. 43, n. 2, p. 105-140, 2000. 
3. BEZERRA, Marcos O. Estado e representação política e corrupção: um olhar antropológico sobre a formação de fronteiras sociais. Crítica e Sociedade: revista de cultura política, v. 2, n. 2, p. 64-80, 2012.

4. BEZERRA, Marcos O. Participação popular e conflitos de representação política: notas a partir de um caso de orçamento participativo. In: PALMEIRA, Moacir; BARREIRA, César. Política no Brasil. Visões de antropólogos. Rio de Janeiro: Relume-Dumará, 2004.

5. BRASIL. Ministério da Educação. Caderno de Orientações para Plano Municipal de Educação. Brasília: MEC, 2015.

6. CÂMARA MUNICIPAL DE NATAL. Procuradoria Legislativa. Parecer técnico Processo n. 15/2016. Natal, abr. 2016.

7. CÂMARA MUNICIPAL DE NATAL. Procuradoria Legislativa. Parecer técnico Processo n. 19/2016. Veto ao item 7.3. Natal, abr. 2016.

8. CÂMARA MUNICIPAL DE NATAL. Procuradoria Legislativa. Parecer técnico Processo n. 23/2016. Veto ao item 20.4. Natal, abr. 2016.

9. CHAVES, Lilian. Antropologia política. Notas de aulas proferidas na UFRN (60 horas), Programa de Pós-Graduação em Antropologia Social, Natal, 2016.

10. DA MATTA, Roberto. Carnaval, malandros e heróis: para uma sociologia do dilema brasileiro. 6. ed. Rio de Janeiro: Rocco, 1997.

11. DUMONT, Louis. O individualismo. Uma perspectiva antropológica da ideologia moderna. Rio de Janeiro: Rocco, 1985.

12. FOUCAULT, Michel. A governamentalidade. Microfísica do poder. 25. ed. São Paulo: Graal, 2012a.

13. FOUCAULT, Michel. Genealogia e poder. Microfísica do poder. 25. ed. Rio de Janeiro: Graal, 2012b.

14. FOUCAULT, Michel. História da sexualidade, vol. 1: a vontade de saber. São Paulo: Graal, 1988.

15. FOUCAULT, Michel. Segurança, território, população. Curso dado no Collège de France (1977-1978). São Paulo: Martins Fontes, 2008.

16. GLUCKMAN, Max. Análise de uma situação social na Zululândia Moderna. In: FELDMAN-BIANCO, Bela. (Org.). Antropologia das sociedades contemporâneas: métodos. São Paulo: Editora UNESP, 2010.

17. KERBAUY, Maria T. M. As câmaras municipais brasileiras: perfil de carreira e percepção sobre o processo decisório local. Opinião Pública, Campinas, v. xi, n. 2, p. 337-365, 2005. 
18. KUSCHNIR, Karina. Antropologia e política. BIB, v. 22, n. 64, p. 163-167, 2007.

19. LEACH, Edmund R. Sistemas políticas da Alta Birmânia. São Paulo: EDUSP, 1996.

20. LOPES, José S. L. Audiência pública em Angra dos Reis: debate em torno do licenciamento de uma usina nuclear. In: PALMEIRA, Moacir; BARREIRA, César. Política no Brasil. Visões de antropólogos. Rio de Janeiro: Relume-Dumará, 2004.

21. NADER, Laura. Up the anthroplogists: perspectives from studying up. In: HYMES, Dell (Ed.). Reinventing Anthropology. New York: Pantheon Books, 1972.

22. NATAL. Fórum Municipal de Educação da Cidade do Natal/RN. Documento-base Plano Municipal de Educação 2015-2025 da cidade do Natal (RN). Versão Preliminar, f. 130, Natal, 2015a.

23. OKONGWU, Anne Francis; MENCHER, Joan P. The anthropology of public policy: shifting terrains. Annual Review of Anthropology, v. 29, p. 107-24, 2000.

24. PEIRANO, Mariza. A análise antropológica de rituais. $\mathbf{O}$ dito e o feito. Rio de Janeiro: Relume-Dumará, 2002.

25. PREFEITURA DE NATAL. Mensagem n. 014/2016. Palácio Felipe Camarão, Natal, abr. 2016.

26. PREFEITURA DE NATAL. Mensagem n. 018/2016. Palácio Felipe Camarão, Natal, abr. 2016.

27. ROCHA, Marta M. da; KERBAUY, Maria T. M. Poder local e representação política nos municípios brasileiros: contribuições para uma agenda de pesquisas. Eleições, partidos e representação política nos municípios brasileiros. Juiz de Fora: Editora UFJF, 2014.

28. SAVIANI, Dermeval. Da nova LDB ao Novo Plano Nacional de Educação: por uma outra política educacional. 5. ed. Campinas: Autores Associados, 2004.

29. SILVA, Bruno S. da. Produção legislativa e relações Executivo-Legislativo no nível local: uma análise das indicações e dos requerimentos na Câmara Municipal de Araraquara. In: ROCHA, Marta M. da; KERBAUY, Maria T. M. (Org.). Eleições, partidos e representação política nos municípios brasileiros. Juiz de Fora: Editora UFJF, 2014.

30. TEIXEIRA, Carla; SOUZA LIMA, Antônio C. A antropologia da administração e da governança no Brasil: área temática ou ponto de dispersão? In: DUARTE, Luiz Fernando Dias (Org.). Horizontes das Ciências Sociais no Brasil: Antropologia. São Paulo: ANPOCS, 2010. 
31. TEIXEIRA, Carla. Pesquisando instâncias estatais: reflexões sobre o segredo e a mentira. In: CASTILHO, Sérgio; SOUSA LIMA, Antônio; TEIXEIRA, Carla. Antropologia das práticas de poder: reflexões etnográficas entre burocratas, elites e corporações. Rio de Janeiro: Contracapa, 2014.

32. VALENTE, Ivan. Plano Nacional de Educação. Rio de Janeiro: DP\&A, 2001. 